\title{
Prey Choice by Facultative Predator Larvae of Chrysomya albiceps (Diptera: Calliphoridae)
}

\author{
Lucas Del Bianco Faria, Wesley Augusto Conde Godoy ${ }^{+}$
}

\begin{abstract}
Departamento de Parasitologia, IB, Universidade Estadual Paulista, Rubião Junior, 18618-000 Botucatu, SP, Brasil
\end{abstract}

In this study we investigated predation rates on third instar larvae of Chrysomya putoria and $\mathrm{C}$. megacephala by third instar larvae of $\mathrm{C}$. albiceps in a two-choice situation. The highest predation rate occurred on C. putoria larvae and this result is compared to previous experiments, in which C. macellaria larvae were present. Our results suggest that, when C. macellaria is absent C. albiceps larvae attack more C. putoria than C. megacephala larvae. Prey choice decisions and its implications for introduced and native blowflies are discussed.

Key words: Chrysomya albiceps - prey choice - larval predation - interspecific interaction - Diptera Calliphoridae

Understanding the patterns and ways in which animals utilize food resources is fundamental to the study of any animal population and community (Gotelli 1995). Foraging efficiency may differ considerably between classes of animals within the population and between individuals within a class (Brewer 1994). Class differences may be related to size or age (Marchetti \& Price 1989, Hirvonen \& Ranta 1996), but even among individuals within a class there may be significant differences in rates of energy intake (Ranta \& Nuutinen 1985, Ehlinger 1989). This might be due to individual abilities in utilizing available prey, but also because individuals utilize different prey species or sizes of those available (Holbrook \& Schmitt 1992).

The most important period of life for some insects, such as blowflies, is the larval stage because in this phase they acquire food and minimum weight necessary to become pupae and subsequently adults (Levot et al. 1979). Blowflies feed usually on carcasses and the amount of food available may influence the population dynamics of many species (Godoy et al. 1993). Carcasses are ephemeral substracts in which many individuals and species are generally present, consuming all food resources in a short period of time and there-

Research supported by grants 97-01441-6, from Fapesp. ${ }^{+}$Corresponding author. Fax: +55-14-821.3744. E-mail: wgodoy@ibb.unesp.br

Received 14 November 2000

Accepted 5 April 2001 fore rarely completing more than one generation inside them (Putman 1977, Hanski 1987).

The blowfly community is a very complex system, including probably many simultaneous processes such as intra and interspecific competition, facultative larval predation and cannibalism (Ullyett 1950, Gagné 1981, Erzinçlioglu \& Whitcombe 1983, Wells \& Greenberg 1992a,b,c). All these interactions have a strong impact on the diptera community, mainly when severe competition takes place (Ullyett 1950, Hanski 1977, Goodbrood \& Goff 1990, Wells \& Greenberg 1992a,c).

Interspecific interactions in blowfly system have been investigated in experiments in which population dynamics and competitive ability of the invading species $C$. rufiffacies and C. albiceps, and of the native species $C$. macellaria were analyzed (Wells \& Greenberg 1992a,b,c, 1994, Wells \& Kurahashi 1997, Faria et al. 1999, Reis et al. 1999, Von Zuben et al. 2000). These investigations were attempts to gain a deeper understanding of recent blowfly biological invasion in Americas and its implications on population dynamics.

There is some evidence in the Americas that the native species $C$. macellaria has been displaced by Chrysomya species (Guimarães et al. 1978, 1979, Prado \& Guimarães 1982). A gradual decline of $C$. macellaria has been observed probably as a consequence of the introduction of Chrysomya species in the New World (Guimarães et al. 1978, 1979, Prado \& Guimarães 1982, Baumgartner \& Greenberg 1984). Additionally, we have strong evidences to believe that the principal prey of $C$. albiceps and $C$. rufifacies during larval stage is $C$. macellaria (Wells \& Greenberg 1992a, Wells \& Kurahashi 1997, Faria et al. 1999). 
In this sense, it would be interesting to investigate if there are other blowfly species that $C$. albiceps can attack when $C$. macellaria is not present. The existence and abundance of alternative prey can be important factors to $C$. albiceps population dynamics, mainly in situations where the natural food source is scarce (Ullyett 1950, Polis 1981, Faria et al. 1999). In this study we extended choice experiments from Faria et al. (1999) to investigate if $C$. albiceps attacks $C$. putoria and $C$. megacephala at the same rate when C. macellaria is not present.

\section{MATERIALS AND METHODS}

Laboratory populations of $C$. albiceps, $C$. putoria and $C$. megacephala were taken from specimens collected from the Campus of the Universidade Estadual Paulista, Botucatu, São Paulo, Brazil. Adult flies were maintained at $25 \pm$ $1^{\circ} \mathrm{C}$ in cages $(30 \times 30 \times 30 \mathrm{~cm})$ covered with nylon and were fed water and sugar ad libitum. Adult females were fed fresh beef liver to permit the complete development of the gonotrophic cycle. Hatched larvae were reared on an excess of ground beef until the third instar in all species studied, when they were taken and introduced in empty vials (7 $\mathrm{cm}$ height $\mathrm{x} 6 \mathrm{~cm}$ diameter) to estimate predation rates in different combinations. Larval instar was determined by using accepted morphological characters used to separate the various development stages of blowflies (Prins 1982, Greenberg \& Szyska 1984, Erzinçlioglu 1987, 1990,Tantawi \& Greenberg 1993, Queiroz et al. 1997).

Predation rates were evaluated in a two-choice experiment, confining one $C$. albiceps larva with two larvae, one of $C$. putoria and one of $C$. megacephala. Forty vials were prepared for each combination, and placed on a lighted laboratory bench at $25^{\circ} \mathrm{C}$. The larvae were continually scanned for $2 \mathrm{~h}$ and instances of predation on C. putoria and C. megacephala, were recorded every $15 \mathrm{~min}$. Predatory behavior was considered successful when $C$. albiceps surrounded and mortally pierced its prey with the pierced larvae struggling violently in response.

The number of killed and surviving larvae of each species was statistically analyzed using $\chi^{2}$ test for homogeneity of rates. Then, the rates of predation on each species were analyzed further by considering only the predation cases. In all comparisons the Yates correction for continuity of the $\chi^{2}$ statistics was used (Zar 1996).

\section{RESULTS AND DISCUSSION}

The highest predation rate by $C$. albiceps larvae $(72.5 \%)$ occurred on $C$. putoria, compared to $15 \%$ on $C$. megacephala (Table). There was no predation in $12.5 \%$ of the vials. These three rates were significantly different $\left(\chi^{2}=25.36 ; d . f .=2\right.$; $P<0.05)$. Considering only the predation cases, $82.9 \%$ was on $C$. putoria and $17.1 \%$ on $C$. megacephala. The $\chi^{2}$ test indicated that there was significant difference between these predation rates $\left(\chi^{2}=13.83 ;\right.$ d. f. $\left.=1 ; P<0.05\right)$.

Our results suggest that, when $C$. macellaria is absent $C$. albiceps larvae attack more $C$. putoria than $C$. megacephala larvae. In a recent paper, Faria et al. (1999) investigated larval predation by $C$. albiceps on C. macellaria, C. megacephala and $C$. putoria. In choice experiments, where all species were confined together, $C$. albiceps killed $C$. macellaria at a larger rate than $C$. megacephala and $C$. putoria. When species were confined in pairs, no choice experiment, $C$. albiceps predated all species practically at the same rate, indicating there is no preference for a specific prey if the predator larvae has no choice of species (Faria et al. 1999).

TABLE

Predation rates by Chrysomya albiceps in a two-choice situation with C. megacephala and C. putoria as the choices

\begin{tabular}{|c|c|c|c|c|}
\hline \multirow{2}{*}{$\begin{array}{l}\text { Time interval } \\
\text { (min) }\end{array}$} & \multicolumn{2}{|c|}{ Chrysomya megacephala } & \multicolumn{2}{|c|}{ Chrysomya putoria } \\
\hline & Predation & Cumulative & Predation & Cumulative \\
\hline 15 & 10 & 10 & 32.5 & 32.5 \\
\hline 30 & 0 & 10 & 5 & 37.5 \\
\hline 45 & 2.5 & 12.5 & 10 & 47.5 \\
\hline 60 & 2.5 & 15 & 17.5 & 65 \\
\hline 75 & 0 & 15 & 2.5 & 67.5 \\
\hline 90 & 0 & 15 & 5 & 72.5 \\
\hline 105 & 0 & 15 & 0 & 72.5 \\
\hline 120 & 0 & 15 & 0 & 72.5 \\
\hline Total & 15 & 15 & 72.5 & 72.5 \\
\hline
\end{tabular}


The flexibility of $C$. albiceps in relation to choice of larvae observed both by Faria et al. (1999) and in this study, suggests that its predatory behavior can be changed as a function of prey availability. In natural settings the coexistence of different species of blowflies in the same substrate is not uncommon (Kneidel 1984a,b, Hanski 1987, Wells \& Greenberg 1994) therefore, larvae of $C$. albiceps probably have a choice of prey.

Diet preference has been investigated in Coleoptera from an evolutionary perspective, since coccinellids exhibit considerable diversity in habitat, dietary preference, and specificity (Sloggett \& Majerus 2000). Feeding in atypical habitats, on alternative food, when optimal prey is scarce, is likely to be a factor of major importance in evolutionary shifts towards novel diets and habitats (Sloggett \& Majerus 2000). The incorporation of a new kind of prey may occur frequently, as a function of main prey scarcity (Hodek 1996).

Different predators may adopt different strategies to utilize food resources. Optimal foraging theory explains how foragers, maximizing their net energy intake, can do this in different types of prey environment (Stephens \& Krebs 1986). How individuals make their prey choice decisions has profound consequences on their own energy input. Prey choice also has consequences on output, i.e. growth, development, and body reserves, which in turn influence maturation age, reproductive success, prey population dynamics, and prey community structure (Calow 1994, Persson et al. 1997). These factors can also be important to predator populations, since changes in larval diet may have implications for population dynamics, retarding larval development rate, affecting adult size, and sometimes suppressing oviposition (Hattingh \& Samways 1992).

Our main question after analyzing the results of Faria et al. (1999) and this study is, what prey species confers more advantages to $C$. albiceps in terms of functional and numerical response, when the food scarceness is the predominant situation? Carrying capacity is an important factor probably implicated in the switching of food source. We believe that under food scarceness, $C$. albiceps is able to change its behavior attacking other blowfly species, as well as using cannibalism as an alternative strategy for population survival.

In an attempt to understand these aspects better, we have investigated intra and interspecific interactions in blowflies. We studied interactions between introduced and native species. Under experimental conditions, $C$. albiceps has caused complete exclusion of $C$. macellaria and $C$. megacephala (pers. obs.). However, when $C$. albiceps is not present, coexistence between Chry- somya species and C. macellaria occurs (Reis et al. 1999). These results have brought important and interesting questions and answers, which have motivated new studies. Biological invasions like this are very complex phenomena and demand careful examination of all aspects involved. The results obtained up to now have helped us to understand part of the mechanism involved in the invasion and colonization processes, but more studies focussing larval behavior, interspecific interactions, and frequency distribution of species are necessary to evaluate in detail the current situation of Brazilian necrophilic fauna structure.

\section{ACKNOWLEDGEMENT}

To the anonymous reviewer for useful comments and suggestions which improved the clarity and content of the manuscript.

\section{REFERENCES}

Baumgartner DL, Greenberg B 1984. The genus Chrysomya (Diptera: Calliphoridae) in the New World. $J$ Med Ent 21: 105-113.

Brewer R 1994. The Science of Ecology, 2nd ed., Saunders College Publishing, Ft. Worth, 773 pp.

Calow P 1994. From physiological ecology to population and evolutionary ecology with speculation on the importance of stored processes. In SR Leather, AD Watt, NJ Mills, KF Walters (eds), Individuals, Population and Patterns in Ecology, Intercept, Andover, p. 349-358.

Ehlinger TJ 1989. Learning and individual variation in bluegill foraging: habitat-specific techniques. Anim Behav 35: 102-114.

Erzinçlioglu YZ 1987. The larvae of some blowflies of medical and veterinary importance. Med Vet Entomol 1: $121-125$

Erzinçlioglu YZ 1990. The larvae of two closely-related blowfly species of the genus Chrysomya (Diptera, Calliphoridae). Entomologica Fennica 3: 151-153.

Erzinçlioglu YZ, RP Whitcombe 1983. Chrysomya albiceps (Wiedemann) (Dipt., Calliphoridae) in dung and causing myiasis in Oman. Entomol Monthly Mag 119: 51-52.

Faria LDB, Orsi L, Trinca LA, Godoy WAC 1999. Larval predation by Chrysomya albiceps on Cochliomyia macellaria, Chrysomya megacephala and Chrysomya putoria. Ent Exp App 90: 149-155.

Gagné RJ 1981. Chrysomya spp., Old World blowflies (Diptera, Calliphoridae), recently established in the Americas. Bull Entomol Soc Am 27: 21-22.

Godoy WAC, Von Zuben CJ, Ribeiro OB 1993. Population dynamics of Chrysomya putoria (Wied.) (Dipt., Calliphoridae). J App Ent 116: 163-169.

Goodbrod JR, ML Goff, 1990. Effects of larval population density on rates of development and interactions between two species of Chrysomya (Diptera: Calliphoridae) in laboratory culture. J Med Entomol 27: 338-343.

Gotelli NJ 1995. A Primer of Ecology, Sinauer Associates, Sunderland, $206 \mathrm{pp}$. 
Greenberg B, Szyska ML 1984. Immature stages and biology of fifteen species of peruvian Calliphoridae (Diptera). Ann Entomol Soc Am 77: 488-517.

Guimarães JH, Prado AP, Buralli AM 1979. Dispersal and distribution of thre e newly introduced species of Chrysomya Robineau-Desvoidy in Brazil (Diptera, Calliphoridae). Rev Bras Entomol 23: 245-255.

Guimarães JH , Prado AP, Linhares AX 1978. Three newly introduced blowfly species in Southern Brazil (Diptera: Calliphoridae). Rev Bras Entomol 22: 53-60.

Hanski I 1977. Biogeography and ecology of carrion flies in the Canary Islands. Ann Entomol Fenn 43: 101-107.

Hanski I 1987. Carrion fly community dynamics: patchiness, seasonality and coexistence. Ecol Entomol 12: 257-266.

Hattingh V, Samways MJ 1992. Prey choice and substitution in Chilicorus spp. (Coleoptera: Coccinellidae). Bull Entomol Res 82: 327-334.

Hirvonen H, Ranta E 1996. Prey to predator size ratio influences foraging efficiency of larval Aeshna juncea dragonflies. Oecologia 106: 407-415.

Hodek I 1996. Food relationships. In I Hodek, A Honek (eds) Ecology of Coccinellidae, Kluwer Academic Publishers, p. 143-238.

Holbrook SJ, Schmitt RJ 1992. Causes and consequences of dietary specialization in surfperches: patch choice and interspecific competition. Ecology 73: 402-412.

Kneidel KA 1984a.Competition and disturbance in communities of carrion breeding diptera. J Anim Ecol 53: 849-865.

Kneidel KA 1984b. The influence of carcass taxon and size on species composition of carrion-breeding Diptera. Am Mid Nat 111: 57-63.

Levot GW, Brown KR, Shipp E 1979. Laval growth of some calliphorid and sarcophagid Diptera. Bull Entomol Res 69: 469-475.

Marchetti K, Price T 1989. Differences in the foraging of juvenile and adult birds: the importance of developmental constraints. Biol Ver 64: 51-70.

Persson L, Diehl S, Eklöv P, Christensen B 1997. Flexibility in fish behaviour: consequences at the population and community levels. In JGJ Godin Behavioural Ecology of Teleost Fishes, Oxford University Press, Oxford, p. 316-343.

Polis GA 1981. The evolution of dynamics of intraspecific predation. Ann Rev Ecol Syst 12: 125-251.

Prado AP, Guimarães JH 1982. Estado atual de dispersão e distribuição do gênero Chrysomya RobineauDesvoidy na região Neotropical (Diptera: Calliphoridae). Rev Bras Entomol 26: 225-231.

Prins AJ 1982. Morphological and biological notes on six African blow-flies (Diptera, Calliphoridae) and this immature stages. Ann South Afr Mus 90: 201217.
Putman RJ 1977. Dynamics of the blowfly, Calliphora erythrocephala, within carrion. J Anim Ecol 46: 853866.

Queiroz MMC, Mello RP, Lima MM 1997. Morphological aspects of the larval instars of Chrysomya albiceps (Diptera, Calliphoridae) reare in the laboratory. Mem Inst Oswaldo Cruz 92: 187-196.

Ranta E, Nuutinen V 1985. Foraging by the smooth newt (Triturus vulgaris) on zooplankton: functional response and diet choice. J Anim Ecol 54: 275-293.

Reis SF, Von Zuben CJ, Godoy WAC. 1999. Larval aggregation for food in experimental population of Chrysomya putoria (Wied.) and Cochliomyia macellaria (F.) (Dipt. Calliphoridae). J App Ent 123: 485-489.

Sloggett JJ, Majerus MEN 2000. Habitat preferences and diet in the predatory Coccinellidae (Coleoptera): an evolutionary perspective. Biol J Linn Soc 70: 63-88.

Stephens DW, Krebs JR 1986. Foraging Theory, Princenton University Press, Princenton, 262 pp.

Tantawi TI, Greenberg B 1993. Chrysomya albiceps and C. rufifacies (Diptera: Calliphoridae): contribution to an ongoing taxonomic problem. J Med Entomol 30: 646-648.

Ullyett GC 1950. Competition for food and allied phenomena in sheep-blowfly populations. Phil Trans Roy Soc Lond B234: 77-174.

Von Zuben CJV, Stangenhaus G, Godoy WAC 2000. Competição larval em Chrysomya megacephala $(\mathrm{F})$ (Diptera: Calliphoridae): efeitos de diferentes níveis de agregação larval sobre estimativas de peso, fecundidade e investimento reprodutivo. Rev Bras Biol 60: 195-203.

Wells JD, Greenberg B 1992a. Rates of predation by Chrysomya rufifacies (Macquart) on Cochliomyia macellaria (Fabr.) (Diptera: Calliphoridae) in the laboratory: effect of predator and prey development. Pan-Pacific Entomologist 68: 12-14.

Wells JD, Greenberg B 1992b. Laboratory interaction between introduced Chrysomya rufifacies and native Cochliomyia macellaria (Diptera: Calliphoridae). Environ Entomol 21: 640-645.

Wells JD, Greenberg B 1992c. Interaction between Chrysomya rufifacies and Cochliomyia macellaria (Diptera: Calliphoridae): the possible consequences of an invasion. Bull Entomol Res 82: 133-137.

Wells JD, Greenberg B 1994. Resource use by an introduced and native carrion flies. Oecologia 99: 181187.

Wells JD, Kurahashi H 1997. Chrysomya megacephala (Fabr.) is more resistant to attack by Chrysomya rufifacies (Marcquart) in laboratory arena than is Cochliomyia macellaria (Fabr.) (Diptera: Calliphoridae). Pan-Pacific Entomologist 73: 16-20.

Zar JH 1996. Biostatistical Analysis, 3rd ed., Prentice Hall, 662 pp. 